\title{
Um modelo macrodinâmico pós-keynesiano de simulação
}

\author{
JOSÉ LUÍS OREIRO \\ FÁBIO HIDEKI ONO*
}

A post-keynesian macro-dynamic model of simulation. The objective of this article is to present the structure and the simulation results of a one-sector macrodynamic model that embeds some elements of the post-keynesian theory. The computational simulation of the model replicates some important features of capitalist dynamics as the phenomenon of cyclical growth, the long-run stability of the profit rate and functional distribution of income, the maintenance of idle-capacity in the long-run and the occurrence of a single episode of deep fall in real economic activity, which is in accordance with the rarity character of great crashes in the history of capitalism. Moreover, the simulation results show that a great reduction in inflation rate will be followed by an increase of financial fragility, increasing the like-hood of a great depression. As a policy advice derived from the simulation results, we can state that the Central Bank should never promote big reductions in inflation rate.

Key-words: post-keynesian economics, computational economics, monetary Policy.

JEL classification: E5, E12.

\section{INTRODUÇÃO}

A principal característica da dinâmica capitalista é a ocorrência de crescimento com flutuações, ou seja, a ocorrência de flutuações no nível de atividade

\footnotetext{
* Respectivamente, Doutor em Economia (IE/UFRJ), Professor do Departamento de Economia da UFPR e Pesquisador do CNPq. E-mail: joreiro@ufpr.br. e Mestre em Desenvolvimento Econômico (UFPR). E-mail: fabiohono@gmail.com. Os autores agradecem aos comentários de Luiz Carlos Bresser-Pereira, Yoshiaki Nakano, Ramón Garcia Fernandez, Luiz Fernando de Paula, Fernando Ferrari Filho, Luiz Antonio Esteves e de dois pareceristas anônimos da Revista de Economia Política. Eventuais falhas remanescentes são, contudo, de nossa inteira responsabilidade. O suporte financeiro do CNPq também é reconhecido. Submetido: março, 2005; aceito: novembro, 2005.
} 
econômica em torno de uma tendência de crescimento do produto real no longoprazo. Essas flutuações são, via de regra, irregulares, mas não-explosivas, isto é, não se observa em nenhuma economia capitalista uma tendência ao aumento da amplitude das flutuações do nível de atividade em torno da tendência de longoprazo.

A literatura heterodoxa usualmente trata o problema da dinâmica capitalista por intermédio de modelos de equações diferenciais ou em diferenças finitas lineares e não-lineares que possuem solução analítica fechada. Os modelos dinâmicos lineares - como, por exemplo, os modelos de Samuelson (1939) e Kalecki (1954) — só são capazes de gerar flutuações constantes do nível de atividade econômica, em torno de uma tendência de crescimento exógenamente determinada, para um conjunto extremamente restrito de valores dos parâmetros das equações dinâmicas. Além disso, essa classe de modelos só é capaz de produzir flutuações regulares (com periodicidade e amplitude constantes) do nível de produto. $\mathrm{O}$ problema é que as flutuações do nível de atividade que são observadas no mundo real são eminentemente irregulares, ou seja, possuem periodicidade e amplitude variáveis. Por outro lado, os modelos dinâmicos não-lineares que admitem solução analítica fechada - como, por exemplo, os modelos de Hicks (1950) e Goodwin (1967) — ou se baseiam em tetos e fundos de natureza arbitrária para gerar flutuações não-explosivas do nível de atividade econômica, ou admitem soluções do tipo ciclo-limite que não reproduzem o caráter irregular das flutuações do produto que são observadas no mundo real.

Em função das limitações dos modelos dinâmicos com solução analítica fechada tem-se observado nos meios heterodoxos um movimento crescente em prol da adoção de modelos dinâmicos de simulação. Tais modelos possuem, via de regra, uma estrutura não-linear, mas o número de equações e a complexidade das relações entre as variáveis endógenas tornam impossível a obtenção de uma solução analítica fechada para os mesmos. Tais modelos admitem apenas soluções por intermédio de simulação computacional, ou seja, a obtenção de trajetórias no tempo para as variáveis endógenas através da solução numérica do modelo. Essa solução numérica é obtida em computador ao se atribuir valores economicamente plausíveis para os parâmetros das equações dinâmicas e para as condições iniciais do modelo.

Um exemplo recente de modelo nessa tradição é Possas et alli (2004). ${ }^{1}$ Esses autores construíram um modelo dinâmico multissetorial que faz uma integração micro-macroeconômica a partir de um enfoque teórico keynesiano e kaleckiano. Os resultados obtidos com as primeiras simulações computacionais do modelo reproduzem alguns traços gerais da dinâmica capitalista como, por exemplo, a ocorrência de flutuações irregulares e não-explosivas do nível de atividade econômica e o papel predominante do investimento em capital fixo na determinação das flutuações do nível de produção.

${ }^{1} \mathrm{O}$ qual é baseado em Possas (1984). 
Apesar dos bons resultados iniciais obtidos com as simulações computacionais do modelo supra-referido, o mesmo apresenta algumas deficiências no que tange a incorporação de elementos da matriz teórica keynesiana e kaleckiana.

Em primeiro lugar, a função investimento postulada pelos autores considera que o investimento desejado pelas firmas depende unicamente da expansão prevista das vendas. Embora o princípio da aceleração seja certamente um elemento importante de qualquer teoria séria a respeito da decisão de investimento, não se pode desconsiderar o fato elementar que os empresários só irão aumentar a sua capacidade produtiva se a expansão da mesma for lucrativa. Isso significa que a decisão de investimento deve ser analisada no contexto mais geral da teoria da aplicação do capital, tal como faz Keynes no capítulo 17 da sua Teoria geral do emprego, do juro e da moeda ${ }^{2}$ Sendo assim, a decisão de investimento deve levar em conta a comparação da rentabilidade da aplicação na expansão da capacidade produtiva existente com a rentabilidade das aplicações financeiras. Dessa forma, uma função investimento mais próxima à teoria dos dois preços de Minsky (1975) seria mais adequada para um modelo que pretende explicar a dinâmica capitalista.

Em segundo lugar, a complexidade introduzida com a estrutura multi-setorial do modelo - complexidade que é aparentemente desnecessária, pois não gera nenhum resultado de simulação que não possa ser obtido com um modelo de um único setor - dificulta a consideração de outros elementos importantes na dinâmica capitalista como, por exemplo, a existência de propensões a poupar diferenciadas com base na classe de rendimentos; ${ }^{3}$ o papel do conflito distributivo da determinação da taxa de inflação; e a influência da taxa de juros na determinação do investimento em capital fixo.

Sendo assim, acreditamos que é desejável a elaboração de um novo modelo macro-dinâmico que, por um lado, incorpore mais elementos do enfoque teórico pós-keynesiano do que aqueles incorporados no modelo de Possas et alli e; por outro lado, não possua uma estrutura multi-setorial, a qual consideramos desnecessária e contra-producente na medida em que eleva a tal ponto a complexidade do modelo de simulação que pode impedir a incorporação de elementos mais relevantes para a explicação da dinâmica capitalista.

Isso posto, o presente artigo tem por objetivo apresentar a estrutura e as primeiras simulações computacionais de um modelo macrodinâmico uni-setorial de filiação teórica pós-keynesiana. Os elementos do enfoque teórico pós-keynesiano incorporados no modelo aqui apresentado são: (i) determinação do nível de pro-

\footnotetext{
${ }^{2}$ A respeito da relação da decisão de investimento em capital fixo e a decisão de composição de portfólio ver Carvalho (1992, cap. 5).

${ }^{3}$ Com efeito, a "função consumo" apresentada pelos autores admite apenas a existência de propensões a consumir diferenciadas com base na faixa de rendimentos. Dessa forma, um importante elemento do enfoque teórico keynesiano/kaleckiano (pós-keynesiano) é desconsiderado pelos autores.
} 
dução pela demanda efetiva; (ii) existência de propensões a poupar diferenciadas com base na classe de rendimentos; (iii) fixação de preços com base num markup sobre os custos diretos unitários de produção; (iv) determinação do investimento com base na teoria dos dois preços de Minsky; (v) influência da estrutura de capital das empresas, em especial o seu nível de endividamento, sobre a decisão de investimento e de fixação de preços; (vi) determinação da taxa de inflação com base no conflito distributivo entre capitalistas e trabalhadores; (vii) endogenidade da oferta de moeda. ${ }^{4}$

As primeiras simulações computacionais do modelo revelam algumas propriedades importantes da dinâmica capitalista tais como a ocorrência crescimento cíclico, ou seja, a ocorrência de flutuações irregulares e não-explosivas da taxa de crescimento do produto real; a estabilidade da taxa de lucro e da distribuição funcional da renda para longos períodos; a manutenção de capacidade de produção excedente no longo-prazo; a ocorrência de um único episódio de queda acentuada do nível de atividade econômica, o que está em conformidade com o caráter raro das grandes depressões na historia do capitalismo.

Um outro resultado interessante é que as simulações computacionais mostram que uma redução muito acentuada da inflação num curto período de tempo tende a ser acompanhada por uma grande fragilização das posições financeiras das empresas, a qual, mais cedo ou mais tarde, culmina numa grande depressão. Como corolário desse resultado segue-se que o Banco Central deve conduzir a política monetária de forma a jamais engendrar quedas muito acentuadas da taxa de inflação.

Dados esses objetivos, o presente artigo está estruturado em cinco seções, incluindo-se a presente introdução. Na seção 2 apresentamos a estrutura básica e as equações do modelo de simulação. Na seção 3 discutimos a metodologia de simulação computacional. A seção 4 apresenta os resultados das primeiras simulações e a seção 5 faz um resumo das conclusões obtidas ao longo do artigo.

\section{A ESTRUTURA BÁSICA DO MODELO DE SIMULAÇÃO}

O presente modelo é composto por cinco módulos interdependentes entre si, quais sejam: (i) módulo 1 - componentes da demanda efetiva; (ii) módulo 2 determinação do nível de produção e renda; (iii) módulo 3 - determinação da distribuição funcional de renda; (iv) módulo 4 - inflação e política monetária; e (v) módulo 5 - sistema financeiro. A estrutura do modelo é tal que o mesmo admite solução recursiva, ou seja, os valores das variáveis dependentes no período $t$ do tempo podem ser todos expressos em termos dos valores dessas mesmas va-

\footnotetext{
${ }^{4}$ A endogeneidade da oferta de moeda não é uma hipótese aceita universalmente pelos economistas pós-keynesianos, sendo defendida principalmente por Kaldor (1982) e Moore (1988).
} 
riáveis no período $t$-1. Sendo assim, uma vez determinados os valores dos parâmetros das equações dinâmicas ${ }^{5}$ e os valores iniciais das variáveis dependentes podemos computar as trajetórias no tempo para todas as variáveis dependentes do modelo ${ }^{6}$. Deve-se ressaltar que as trajetórias assim determinadas não possuem atratores ou tendência pré-determinada, ou seja, o modelo não pressupõe a existência de nenhum tipo de equilíbrio, entendido como o estado terminal ou posição assintótica do sistema econômico.

\section{Módulo 1: Demanda efetiva}

Neste módulo são definidos os componentes e as relações funcionais da demanda efetiva. Deve-se ressaltar que estaremos trabalhando com uma economia fechada, mas com governo, de forma que a demanda efetiva é constituída pela soma dos gastos de consumo, investimento público e privado e gastos do governo.

Inicialmente, iremos assumir que os gastos do governo com investimento em capital fixo aumentam a uma taxa exógena $\left(b^{I}\right)$ por período, ou seja, que os mesmos são autônomos com respeito ao nível corrente de atividade econômica. Dessa forma, podemos escrever a seguinte equação:

$$
G_{t}^{I}=\left(1+b^{1}\right) G_{t-1}^{I}
$$

Onde: $G^{I} T$ é o investimento público realizado no período $t$.

O governo também realiza gastos de consumo, os quais estão relacionados fundamentalmente com o pagamento do funcionalismo público e transferências de renda para o setor privado. Iremos assumir que os gastos de consumo do governo são pró-ciclicos, ou seja, variam na mesma direção do nível de atividade econômica. Sendo assim, temos que:

$$
G_{t}^{C}=b^{C} Y_{t-1}
$$

\footnotetext{
${ }^{5} \mathrm{O}$ modelo que será apresentado a seguir é um modelo estrutural, ou seja, um modelo que parte da especificação das relações estruturais entre as variáveis econômicas - por exemplo, a função investimento - para estudar a interação dessas variáveis no tempo. Uma crítica comum de economistas ligados à velha tradição neoclássica de economia é que modelos estruturais (sic) ignoram os microfundamentos (neoclássicos) e, dessa forma, estariam sujeitos à crítica de Lucas, ou seja, à crítica de que os parâmetros das equações estruturais desses modelos não são invariantes com respeito a mudanças na política econômica. Isso porque, tal como afirmam Lucas e Sargent (1994, p. 19), alterações na política econômica produzem mudanças nas expectativas dos agentes, as quais são determinantes importantes dos parâmetros dos modelos estruturais que não possuem micro-fundamentos. Esta crítica não é aplicável, contudo, a modelos estruturais pós-keynesianos uma vez que a teoria pós-keynesiana rejeita radicalmente a hipótese de expectativas racionais (Cf. Davidson, 1988), a qual é o fundamento teórico da crítica de Lucas.

${ }^{6}$ Nas simulações do modelo aqui apresentadas iremos utilizar a planilha EXCEL para o cálculo das trajetórias temporais das variáveis endógenas do modelo.
}

${ }^{7}$ Uma hipótese similar a esta é adotada por Hicks (1950). 
Onde: $h^{C}$ representa o fator de indução das variações do nível de atividade econômica do período $t$-1 sobre os gastos de consumo do governo no período $t$. Por hipótese: $1>b^{C}>0$.

$\mathrm{O}$ investimento privado na ampliação da capacidade produtiva existente é determinado por um processo de dois estágios. No primeiro estágio, determina-se o investimento que os empresários desejam realizar dadas as suas expectativas quanto aos rendimentos futuros do equipamento de capital, o seu estado de confiança e a sua preferência pela liquidez que se manifestam na determinação do fator de desconto aplicado a série de rendimentos futuros esperados do novo equipamento de capital. No segundo estágio, os empresários confrontam o investimento desejado com a restrição financeira ao investimento, expressa pelo nível máximo de endividamento que a firma pode tolerar. Se o investimento desejado for superior ao investimento possivel, dada a restrição financeira da firma, então a firma só poderá investir até o máximo permitido pelo seu nível de endividamento. Por outro lado, se o investimento desejado for inferior ao investimento possível então a firma poderá executar a totalidade das suas decisões de investimento.

$\mathrm{O}$ investimento desejado possui um componente autônomo que capta o otimismo espontâneo ou o animal spirits dos investidores. Iremos supor que este componente autônomo é uma fração constante $\left(a_{0}\right)$ do estoque de capital das empresas do período anterior. Além desse componente autônomo, o investimento desejado depende da razão entre o valor presente dos rendimentos esperados do equipamento de capital ao longo de sua vida útil $\left(\mathrm{PD}_{t}\right)$ e o custo de reposição do capital $\left(P_{t}{ }_{t}\right)$. Esse segundo componente visa inserir a decisão de investimento no contexto mais geral da teoria da aplicação do capital, onde a compra de bens de capital é vista apenas como uma das formas possíveis de acumulação de riqueza ao longo do tempo, cuja atratividade depende da sua rentabilidade vis-à-vis a rentabilidade das demais formas de acumulação de riqueza. Dessa forma, a função de investimento desejado pode ser expressa por:

$$
I_{t}^{D}=\left\{\begin{array}{l}
\alpha_{0} K_{t-1}+\alpha_{1}\left(\frac{P_{t}^{D}}{P_{i}^{S}}-1\right) ; \text { se } P_{t}^{D}>P_{i}^{S} \\
\alpha_{0} K_{t-1} \text { c.c. }
\end{array}\right.
$$

onde: $\alpha_{0}>0 ; \alpha_{1}>0$

$\mathrm{O}$ valor presente dos rendimentos esperados do equipamento de capital, o qual podemos denominar de preço de demanda do equipamento de capital, pode ser calculado ao se assumir um comportamento convencional de formação de expectativas, ou seja, ao se assumir que os lucros futuros serão iguais aos lucros obtidos no período imediatamente anterior ao da tomada da decisão de investimento ${ }^{8}$. Dessa forma, temos que:

\footnotetext{
${ }^{8}$ Sobre a racionalidade desse padrão de expectativas ver Possas (1993).
} 


$$
P_{t}^{D}=\frac{(1-\tau) m_{t-1} P_{t-1} Y_{t-1}}{d_{t}}
$$

Onde: $\tau$ é a alíquota do imposto sobre os rendimentos não-salário; $m_{t-1}$ é a participação dos lucros na renda no período $t-1 ; P_{t-1}$ é o nível geral de preços do período $t-1 ; Y_{t-1}$ é a renda real do período $t-1$ e $d_{t}$ é a taxa de desconto aplicada aos rendimentos esperados do equipamento de capital.

O custo de reposição do equipamento de capital, o qual podemos denominar de preço de oferta do referido equipamento, nada mais é do que o valor do estoque de capital avaliado aos preços correntes desse equipamento. ${ }^{9}$ Dada a estrutura uni-setorial do modelo aqui apresentado, o preço corrente do equipamento de capital é igual ao nível geral de preços prevalecente no período. Sendo assim, temos que:

$$
P_{t}^{S}=P_{t-1} Y_{t-1}
$$

Iremos assumir que a taxa de desconto aplicada aos rendimentos esperados do equipamento de capital depende de dois elementos, a saber: a taxa de juros bancária $\left(i_{t-1}\right)$ e o risco do tomador, o qual é uma média ponderada do risco de solvência $\left(\delta_{\mathrm{t}-1}\right)$ e do risco de refinanciamento ou liquidez $\left(f_{t-1}\right)$. Sendo assim, temos que:

$$
d_{t}=i_{t-1}+\theta\left[\frac{L_{t-1}}{P_{t-1} K_{t-1}}\right]+(1-\theta)\left[\frac{\left(i_{t-1}+\gamma\right) L_{t-1}}{m_{t-1} P_{t-1} Y_{t-1}}\right]=i_{t-1}+\theta \delta_{t-1}+(1-\theta) f_{t-1}
$$

Onde: $L_{t}$ é o total de empréstimos concedidos pelos bancos; $\theta$ é o fator de ponderação entre os riscos de solvência e de liquidez (esse fator reflete o grau de aversão das firmas ao risco de insolvência vis-à-vis o risco de liquidez); $\gamma$ é o coeficiente de amortização das dívidas das empresas, $\delta_{t-1}$ é o endividamento total das empresas como proporção do estoque de capital (o qual determina o risco de solvência); e $f_{t}$ é a razão entre os compromissos financeiros das empresas (equivalente à soma dos juros devidos com a amortização do principal) e o lucro operacional da empresa (essa razão determina o risco de liquidez da firma, ou seja, o grau no qual a firma está exposta à situação de não ser capaz de honrar os seus compromissos contratuais).

Uma vez determinado o investimento desejado, as firmas devem avaliar a real possibilidade de implementação de suas decisões de investimento. Para tan-

\footnotetext{
${ }^{9}$ Para manter o caráter recursivo do modelo aqui exposto, iremos avaliar o custo de reposição do equipamento de capital com base nos preços e no estoque de capital prevalecente ao final do período $t-1$.
} 
to, elas devem determinar o montante de empréstimos que podem contrair junto ao setor bancário, tendo em vista o grau máximo de endividamento que as mesmas estão dispostas a aceitar; bem como o montante de recursos próprios efetivamente disponíveis para o financiamento de suas decisões de investimento. Em outras palavras, a restrição financeira ao investimento é igual ao acréscimo no nível de endividamento junto aos bancos comerciais que as firmas estão dispostas a aceitar mais o lucro operacional líquido não-distribuído aos acionistas ${ }^{10}$. Sendo assim, o investimento que a firma pode realizar no período $t$ é determinado por:

$$
F_{t}=\delta_{\max } P_{t-1} K_{t-1}-L_{t-1}+S_{c}(1-\tau)\left[P_{t-1} Y_{t-1}-w_{t-1} N_{t-1}-\left(i_{t-1}+\gamma\right) L_{t-1}\right]
$$

O primeiro termo do lado direito na expressão (6) representa o montante máximo de endividamento que as empresas estão dispostas a contrair junto aos bancos comerciais no período $t$. Ao subtrairmos desse termo o total de empréstimos contraídos ate o período $t$-1, obtemos o acréscimo máximo do endividamento que as empresas estão dispostas a aceitar no período $t$. O termo em colchetes na expressão (6) representa o lucro operacional, ou seja, o lucro bruto (igual à receita operacional das firmas menos o custo operacional que, por hipótese, é igual à folha de salários) menos o pagamento dos encargos financeiros devidos aos bancos comerciais (juros + amortizações). Sobre esse montante incide o imposto de renda cuja alíquota é suposta ser igual a $t$. Uma vez deduzido o pagamento do imposto de renda, obtemos o lucro operacional líquido. Uma parte desse lucro será distribuída para os acionistas na forma de dividendos e bonificações. Nesse contexto, se os capitalistas não forem apenas os proprietários das empresas, como também os seus efetivos administradores; então poderemos supor que o coeficiente de retenção de lucros é, na verdade, igual à propensão a poupar a partir do lucro operacional líquido. ${ }^{11}$ Ou seja, poderemos supor que os lucros retidos são iguais à poupança dos capitalistas. ${ }^{12}$

O investimento efetivamente realizado no período $t$ é dado por:

$$
I_{t}+\min \left(I_{t}^{D}, F_{t}\right)
$$

No que se refere aos gastos de consumo, iremos assumir a existência de propensões a consumir diferenciadas sobre salários e lucros, tal como Kaldor (1956) e Pasinetti (1961-62). Mais especificamente iremos assumir que os trabalhadores

\footnotetext{
${ }^{10}$ Com base em Securato (2002, p.71) define-se o lucro operacional como sendo igual ao lucro bruto menos o pagamento dos encargos financeiros da empresa (juros + amortizações do principal). O lucro operacional líquido é igual ao lucro operacional deduzido do pagamento (previsto) de imposto de renda. O lucro retido será, portanto, igual ao lucro operacional liquido menos o pagamento de dividendos e bonificações para os acionistas.

${ }^{11}$ Em outros termos: estamos assumindo que não existe nenhuma diferença entre a "poupança pessoal dos capitalistas" e a "poupança das corporações", ou seja, os capitalistas são as corporações.

${ }^{12}$ Isso significa que os capitalistas consomem a totalidade dos lucros distribuídos.
} 
gastam tudo o que ganham, ou seja, que a propensão a poupar dos trabalhadores é igual a zero. Por outro lado, iremos assumir que os capitalistas produtivos (ou seja, os proprietários das empresas não-financeiras da economia) têm uma propensão a poupar sobre o lucro operacional liquido igual à $s_{c}$; ao passo que os capitalistas financeiros (ou seja, os proprietários dos bancos) têm uma propensão a poupar sobre a receita líquida das operações de intermediação financeira igual à $s_{f}$. Dessa forma, os gastos nominais de consumo no período $t$ são determinados pela seguinte expressão:

$$
P_{t} C_{t}=w_{t-1} N_{t-1}+\left(1-s_{c}\right)(1-\tau)\left[P_{t-1} Y_{t-1}-w_{t-1} N_{t-1}-\left(i_{t-1}+\gamma\right) L_{t-1}\right]+\left(1-s_{f}\right)(1-\tau) i_{t-1} L_{t-1}
$$

Dividindo-se a equação (8) por $P_{t}$, temos após os algebrismos necessários que:

$$
C_{t}=\frac{1}{\left(1+\pi_{t}\right)}\left[V_{t-1} N_{t-1}+\left(1-s_{c}\right)(1-\tau)\left(Y_{t-1}-V_{t-1} N_{t-1}-\left(i_{t-1}+\gamma\right) \delta_{t-1} K_{t-1}\right)+\left(1-s_{f}\right)(1-\tau) i_{t-1} \delta_{t-1} K_{t-1}\right]
$$

Por fim, a demanda efetiva no período $t$ é determinada pela seguinte expressão:

$$
Z_{t}+C_{t}+I_{t}+G_{t}^{c}+G_{t}^{I}
$$

\section{Módulo 2: Produção e renda}

De acordo com o princípio da demanda efetiva, o nível de produção é determinado pela demanda efetiva por bens e serviços (cf. Pasinetti, 1997, p. 99). O único pressuposto teórico para a validade do referido princípio é a existência de capacidade de produção ociosa. ${ }^{13}$ Nesse contexto, as firmas irão atender a qualquer variação da demanda por intermédio de variações do nível corrente de produção.

O limite de validade do referido princípio é dado, portanto, pelo nível potencial de produção da economia, o qual é definida como a quantidade máxima de bens e serviços que a economia pode produzir, num dado período, com o estoque de máquinas e de trabalhadores disponíveis. A determinação do produto potencial envolve, portanto, limitações de duas naturezas distintas, a saber: as limitações à disponibilidade da força de trabalho e as limitações à intensidade do uso da capacidade de produção existente.

No que se refere às limitações da disponibilidade da força de trabalho, devemos atentar para o fato de que existe um nível mínimo abaixo do qual a taxa de desemprego não pode cair. ${ }^{14}$ Essa taxa mínima de desemprego pode ser conside-

\footnotetext{
${ }^{13}$ Deve-se ressaltar que a existência de preços fixos não é condição necessária para a validade do princípio da demanda efetiva. No modelo aqui apresentado, os preços são determinados no início do período e permanecem constantes até o final do mesmo. Contudo, os preços são flexíveis ao longo de uma seqüência de períodos. De fato, os preços podem variar ao longo do tempo tanto em função de variações do nível de salário nominal como em função de variações da taxa de mark-up.
}

${ }^{14}$ Trata-se do assim chamado "desemprego friccional" e do "desemprego voluntário". 
rada como o pleno-emprego da força de trabalho. Denominando essa taxa mínima de desemprego por $U_{\text {min }}$, temos que a produção máxima de bens e serviços possibilitada pelo pleno-emprego da força de trabalho é dada por:

$$
Y_{t}^{\max , l}=\frac{N_{t}}{q_{t}}=\left(1-U_{\min }\right)
$$

Onde: $q_{t}$ é o requisito unitário de mão-de-obra, ou seja, a quantidade de trabalhadores que é tecnicamente necessária para a produção de uma unidade de produto.

Além disso, existe um limite superior ao grau de utilização da capacidade instalada. Tal como enfatizado por Steindl (1952), as firmas desejam operar com uma certa capacidade excedente no longo-prazo. Isso devido à ocorrência de indivisibilidades na decisão de investimento em capital fixo, indivisibilidades essas que fazem com que a capacidade instalada cresça obrigatoriamente na frente da demanda, gerando uma certa ociosidade na utilização da capacidade instalada. Denominando o grau máximo de utilização da capacidade produtiva por $u^{\max }$, temos que a produção máxima de bens e serviços compatível com esse nível de utilização da capacidade instalada é dada por:

$$
Y_{t}^{\max , c}=u^{\max } \bar{Y}_{t-1}
$$

Onde: $\bar{Y}_{t-1}$ é o nível de produção máximo que poderia ser obtido no período t-1 com a plena-utilização da capacidade produtiva existente.

Esse nível máximo de produção é determinado pela seguinte expressão:

$$
\bar{Y}_{t-1}=\sigma K_{t-1}
$$

Onde: $\sigma$ é a "produtividade social do capital"; ${ }^{15}$ ou seja, uma variável de natureza técnica que indica a quantidade de produto que pode ser obtida por intermédio da utilização de uma unidade de "capital".

Nesse contexto, o produto potencial no período $t$ é menor valor entre (11) e (12). Temos, portanto, que:

$$
Y_{t}^{\max }=\min \left[\frac{N_{t}}{q_{t}}\left(1-U_{\text {min }}\right) ; u^{\max } \sigma K_{t-1}\right]
$$

Se o nível efetivo de produção for menor do que o produto potencial determinado pela equação (14), então o produto real no período $t$ será determinado pela demanda efetiva desse mesmo período, dada pela equação (10). Ou seja:

$$
Y_{t}=\min \left[Z_{t}, Y_{t}^{\max }\right]
$$

${ }^{15}$ Essa terminologia é tomada emprestada de Domar (1946). 
No entanto, devemos também levar em conta a existência de um limite ao ritmo no qual a produção pode aumentar entre períodos. Isso porque as firmas se defrontam com um custo não-desprezível para aumentar a produção entre um período e outro, custo esse dado pelas despesas que as mesmas têm que incorrer na seleção, contratação e treinamento dos novos trabalhadores. Sendo assim, iremos assumir a existência de uma taxa máxima de crescimento do produto real entre períodos, a qual é determinada pelo custo máximo de ajuste do nível de produto inter-períodos que as firmas estão dispostas a aceitar. Denominando essa taxa por $g^{\max }$, segue-se que o produto real no período $t$ tem que obedecer a seguinte restrição:

$$
Y_{t} \leq\left(1+g^{\max }\right) Y_{t-1}
$$

Desse razoado se segue que o nível de produção no período $t$ é determinado pela seguinte expressão:

$$
Y_{t}=\min \left[Z_{t}, Y_{t}^{\max },\left(1+g^{\max }\right) Y_{t-1}\right]
$$

Por fim, o estoque de capital no período $t$ é dado por:

$$
K_{t}=(1-\psi) K_{t-1}+I_{t}+G_{t}^{I}
$$

Onde: $\psi$ é a taxa de depreciação do estoque de capital.

\section{Módulo 3: Distribuição de renda.}

Numa economia industrial, a renda deve ser concebida como a riqueza expressa em termos materiais (produtos) e criada ao longo de um determinado período. Sendo assim, há somente duas modalidades de renda, a saber: salários e lucros brutos. O governo e o setor financeiro não criam riqueza, eles apenas se apropriam de uma parte dos lucros gerados no processo produtivo, sob a forma de impostos e juros. Dessa forma, os impostos e os juros não afetam o montante de lucros e, portanto, de renda criada na economia ao longo de um determinado período. ${ }^{16}$

Com base nessas idéias, a renda avaliada em termos nominais e gerada ao longo do período $t$ é igual à soma da massa de salários e dos lucros brutos. Temos, então, que:

\footnotetext{
${ }^{16}$ Sendo assim, está implícito que a taxa de juros não afeta a distribuição de renda entre salários e lucros, mas causa apenas uma redistribuição dos lucros totais gerados ao longo do processo produtivo entre os capitalistas produtivos (empresários) e os capitalistas financeiros (banqueiros). Essa idéia remonta aos economistas clássicos e a Marx. Com efeito, Marx (1988) considera no capítulo 21 do livro 3 de O Capital, intitulado "O Capital como portador de juros", que os juros são uma parte da mais-valia criada pelos trabalhadores produtivos, sendo assim uma dedução dos lucros apropriados pelos capitalistas industriais.
} 


$$
P_{t} Y_{t}=w_{t} N_{t}+r_{t} P_{t} K_{t}
$$

Onde: $r_{t}$ é a taxa de lucro.

Dividindo-se (19) por $P_{t} Y_{t}$, obtemos após os algebrismos necessários que:

$$
1=V_{t} q_{t}+\frac{r_{t}}{\sigma u_{t}}
$$

Onde: $V_{t}=\frac{w_{t}}{P_{t}}$ é o salário real; $q_{t}$ é o requisito unitário de mão-de-obra.

A taxa de lucro $r_{t}$ pode ser expressa como o produto entre a participação dos lucros na renda $\left(m_{t}\right)$, o grau de utilização da capacidade produtiva $\left(u_{t}\right)$ e a produtividade social do capital $(\sigma)$. Sendo assim, a expressão (20) pode ser reescrita como:

$$
m_{t}=1-V_{t} q_{t}
$$

A expressão (21) mostra que, dada a produtividade do trabalho, existe uma relação inversa entre o salário real e a participação dos lucros na renda.

\section{Módulo 4: inflação e política monetária.}

$\mathrm{Na}$ economia aqui considerada se supõe a existência de uma estrutura de mercado oligopolizada de forma que as empresas têm poder de fixação de preços. Estes são fixados com base na imposição de uma taxa de mark-up sobre os custos diretos unitários de produção. Dessa forma, temos que:

$$
P_{t}=\left(1+z_{t}^{f}\right) w_{t} q_{t}
$$

Onde: $z_{t}^{f}$ é a taxa de mark-up fixada pelas empresas do setor produtivo.

Nesse contexto, os preços fixados pelas empresas do setor produtivo podem variar entre períodos em função da ocorrência de (i) uma variação dos salários entre períodos $;{ }^{17}$ e (ii) uma variação da taxa de mark-up entre períodos ${ }^{18}{ }^{19}$. Sendo assim, a taxa de inflação no período $t$, definida como a variação de preços entre o período $t$ e o período $t$-1, é dada por:

\footnotetext{
${ }^{17}$ Estamos supondo que, ao longo de um dado período, os salários nominais são fixos.

${ }^{18}$ Ao contrário dos modelos kaleckianos tradicionais, estamos supondo que a taxa de mark-up pode variar ao longo do tempo como resultado do aumento do poder de mercado das empresas ou em função de uma maior necessidade de geração de fundos próprios para o financiamento das decisões de investimento. Ao longo de um dado período, no entanto, a taxa de mark-up permanece constante.

${ }^{19}$ Estamos supondo a ausência de progresso tecnológico de forma que a produtividade do trabalho é mantida constante ao longo do tempo.
} 


$$
\left(1+\pi_{t}\right)=\frac{P_{t}}{P_{t-1}}=\left[\frac{\left(1+z_{t}^{f}\right)}{\left(1+z_{t-1}^{f}\right)}\right]\left[\frac{w_{t}}{w_{t-1}}\right]
$$

Onde: $\pi_{t}$ é a taxa de inflação no período $t$.

O primeiro passo para a determinação da taxa de inflação no período $t$ é, portanto, a determinação da inflação salarial, ou seja, a determinação da taxa de variação dos salários nominais entre o período $t$ e o período $t$ - 1 . Para tanto, iremos supor que os salários nominais são objeto de barganha entre as firmas e os sindicatos. No processo de negociação salarial, os sindicatos demandam reajustes salariais que sejam suficientes para (a) cobrir a inflação do período anterior e (b) aumentar o nível de salário real até um certo patamar desejado pelos mesmos, o qual é influenciado pelas condições vigentes no mercado de trabalho. Quanto maior for o poder de barganha dos sindicatos, maior será a importância deste último elemento na determinação da taxa de reajuste dos salários nominais. Dessa forma, a equação de reajuste salarial é dada por: ${ }^{20}$

$$
\left(\frac{w_{t}-w_{t-1}}{w_{t-1}}\right)=\left(\frac{P_{t-1}-P_{t-2}}{P_{t-2}}\right)+\varphi\left(\bar{V}_{t}-V_{t-1}\right)
$$

Onde: $\bar{V}_{t}$ é o salário real desejado pelos trabalhadores no período $t$.

Iremos supor que o salário real desejado é uma função inversa da taxa de desemprego $\left(U_{t}\right)$, ou seja:

$$
\bar{V}_{t}=\phi_{1}-\phi_{0} U_{t-1}
$$

Substituindo (24) em (23), temos após os algebrismos necessários que:

$$
\left[\frac{w_{t}}{w_{t-1}}\right]=\left(1+\pi_{t-1}\right)+\varphi \phi_{1}-\varphi \phi_{0} U_{t}-\varphi V_{t-1}
$$

No que se refere à variação da taxa de mark-up entre períodos, iremos nos basear nas idéias de Eichner (1980). Segundo esse autor, a margem de lucro é uma variável central na adaptação da firma a conjuntura econômica. Num cenário positivo de aumento do grau de utilização da capacidade produtiva, as firmas aumentariam a taxa de mark-up devido ao aumento do seu poder de mercado decorrente do aumento da demanda pelos seus produtos. Por outro lado, a margem de lucro é uma variável importante na determinação da capacidade interna de financiamento da firma. Dessa forma, num cenário de elevação da taxa de endividamento, as firmas podem recorrer ao aumento da taxa de mark-up como

${ }^{20}$ Essa equação de reajuste salarial é inspirada em Blanchard (1999, pp. 280-85). 
parte de uma estratégia com vistas ao aumento dos fundos autogerados. Sendo assim, propomos a seguinte equação para a determinação do mark-up das firmas do setor produtivo.

$$
z_{t}^{f}=z_{0}+z_{1}^{f} u_{t-1}+z_{2}^{f} \delta_{t-1}, z_{1}^{f}>0, z_{2}^{f}>0
$$

Daqui se segue que a variação da taxa de mark-up entre períodos é determinada com base na seguinte equação:

$$
\left[\frac{1+z_{t}^{f}}{1+z_{t-1}^{f}}\right]=\frac{1+z_{0}+z_{1}^{f} u_{t-1}+z_{2}^{f} \delta_{t-1}}{1+z_{0}+z_{1}^{f} u_{t-2}+z_{2}^{f} \delta_{t-2}}
$$

Substituindo (27) e (25) em (22), obtemos a expressão que determina a taxa de inflação no período $t$ :

$$
\pi_{t}=\left[\frac{1+z_{0}+z_{1}^{f} u_{t-1}+z_{2}^{f} \delta_{t-1}}{1+z_{0}+z_{1}^{f} u_{t-2}+z_{2}^{f} \delta_{t-2}}\right]\left(\pi_{t-1}+1+\varphi \phi_{1}-\varphi \phi_{0} U_{t-1}-\varphi V_{t-1}\right)-1
$$

O controle da taxa de inflação é um dos objetivos primordiais dos bancos centrais, os quais são as instituições responsáveis pela formulação da política monetária. Não há, todavia, um consenso sobre qual é a melhor conduta na utilização dos instrumentos de política monetária. Ainda que nenhum Banco Central atualmente busque controlar a taxa de crescimento dos agregados monetários, não existe um consenso sobre a primazia das regras sobre as políticas discricionárias ou vice-versa. Blinder $(1999$, p. 58$)$ afirma que os bancos centrais são mais propensos a adotar uma regra baseada em resultados (estabelecendo, por exemplo, metas para a inflação ou para o crescimento do PIB nominal) do que regras baseadas em instrumentos (como a regra de Friedman). Isso decorre da constatação de que os bancos centrais não têm um controle perfeito sobre a taxa de inflação e demais variáveis macroeconômicas, mas que podem exercer uma influência importante sobre as mesmas por intermédio de seus instrumentos. Nesse contexto, se firmou um consenso de que o principal instrumento de política monetária é a taxa de juros.

\footnotetext{
${ }^{21}$ A equação (28) nada mais é do que uma versão turbinada da curva de Phillips expandida pelas expectativas. Observemos a presença de um claro componente inercial na taxa de inflação, expresso pela dependência da taxa de inflação corrente com respeito à taxa de inflação do período anterior (cf. Bresser-Pereira, Nakano, 1984). Observemos também que, ceteris paribus, existe uma clara relação inversa entre a taxa de inflação do período $t$ e a taxa de desemprego do período $t-1$. A novidade introduzida por essa versão turbinada é a possibilidade de deslocamentos ao longo do tempo da curva de Phillips em função do ajuste da taxa de mark-up, o qual é motivado pelas variações no tempo do grau de utilização da capacidade produtiva e da taxa de endividamento.
} 
Isso posto, iremos supor que a política monetária é conduzida num regime de metas de inflação, e que o Banco Central fixa a cada período o valor da taxa básica de juros por intermédio de uma regra de Taylor (cf. Taylor, 1993), tal como a apresentada abaixo: ${ }^{22}$

$$
i^{*}{ }_{t}+(1-\lambda) i^{*}{ }_{t-1}+\lambda\left[\beta_{0}\left(\pi_{t-1}-\pi^{*}\right)+\beta_{1}\left(g_{t-1}-\eta\right)+\beta_{2}\right]
$$

Onde: $i *$ é a taxa básica de juros definida pelo Banco Central; $\lambda$ é o fator de inércia da taxa de juros ${ }^{24}$; os coeficientes $\beta_{0}>0$ e $\beta_{1}>0$ representam, respectivamente, o peso dado, na formação da taxa básica de juros, a divergência da taxa de inflação do período anterior com respeito à meta inflacionária $\left(\pi^{*}\right)$ e a divergência da taxa de crescimento do produto real no período anterior com respeito à taxa natural de crescimento $(\eta)$; e $\beta_{2}$ é uma constante.

A única restrição à aplicação da equação (29) como regra de fixação da taxa básica de juros pelo Banco Central é que a taxa de juros básica não pode jamais ser negativa. Dessa forma, deve-se estabelecer um piso para a taxa básica de juros nessa economia ${ }^{25}$. Denominando esse piso por $i^{*}$ min o valor da taxa básica de juros no período $t$ é dado por:

$$
i^{*}{ }_{t}=\max \left\{i_{\min }^{*} ;(1-\lambda) i_{t-1}^{*}+\lambda\left[\beta_{0}\left(\pi_{t-1}-\pi^{*}\right)+\beta_{1}\left(g_{t-1}-\eta\right)+\beta_{2}\right]\right\}
$$

\section{Módulo 5: Setor financeiro}

Tal como no caso do setor produtivo, iremos supor que a estrutura de mercado prevalecente no setor bancário é oligopolista, de forma que os bancos têm

\footnotetext{
${ }^{22}$ Essa hipótese merece um tratamento mais cuidadoso. Isso porque há uma quase unanimidade entre os economistas pós-keynesianos no que se refere a rejeição do regime de metas de inflação, como arcabouço de condução da política monetária, e do uso da taxa de juros como instrumento de combate à inflação (a esse respeito ver Davidson, 1994). No entanto, a equação (29) deve ser entendida não como uma proposição a respeito de como o Banco Central deveria se comportar caso seguisse os preceitos teóricos pós-keynesianos; mas sim como uma proposição a respeito de como os Bancos Centrais se comportam, de fato, no mundo real. Em outras palavras, a equação (29) está no âmbito da economia positiva, não no âmbito da economia normativa. Neste campo, vários economistas póskeynesianos têm construído modelos nos quais a taxa de juros é determinada pelo Banco Central com vistas ao controle do processo inflacionário. O exemplo clássico desse procedimento é o modelo de crescimento de Joan Robinson (1988). No modelo de Robinson, se a taxa desejada de crescimento do estoque de capital for maior do que a taxa de crescimento possível, então a economia se defrontará com uma barreira inflacionária, a qual levará o Banco Central a aumentar a taxa de juros.

${ }^{23}$ Essa equação da regra de Taylor é inspirada na equação utilizada pelo sistema de metas de inflação implementado pelo Banco Central do Brasil.

${ }^{24}$ Segundo Barbosa (2004), os bancos centrais não realizam mudanças abruptas na taxa de juros de um período para o outro, mas tendem a se comportar de forma a realizar uma suavização dos movimentos da taxa de juros ao longo do tempo. Dessa forma, passa-se a observar um certo comportamento inercial da taxa de juros.
}

${ }^{25}$ A justificativa teórica para a existência desse piso é a armadilha da liquidez apresentada por Keynes na Teoria Geral. 
poder para fixar a taxa de juros cobrada sobre os empréstimos que os mesmos realizam para as empresas daquele setor. Desta forma, os bancos comerciais definem a taxa de juros cobrada pelos seus empréstimos $\left(i_{t}\right)$ por intermédio da aplicação de um mark-up $\left(z_{t}^{b}\right)$ sobre a taxa básica de juros definida pelo Banco Central (cf. Rousseas, 1986, pp. 51-52). Temos, assim, que:

$$
i_{t}=\left(1+z_{t}^{b}\right) i_{t}^{*}
$$

De forma análoga às firmas do setor produtivo, iremos supor que o mark-up bancário não é fixo, mas pode variar entre períodos em função de mudanças na conjuntura econômica e/ou no poder de mercado dos bancos. Nesse contexto, iremos supor que o mark-up bancário é contra-cíclico, variando na direção inversa do grau de utilização da capacidade produtiva (cf. Aronovich, 1994). A idéia é que aumentos no grau de utilização da capacidade produtiva estão associados a aumento das vendas e, portanto, a uma redução do risco de default por parte das empresas do setor produtivo. Essa redução do risco de default permite aos bancos reduzir o spread entre a taxa de juros dos empréstimos e a taxa básica de juros. Por outro lado, iremos supor que aumentos da taxa de inflação irão induzir os bancos comerciais a aumentar a taxa de mark-up (Ibid.). A intuição aqui é que aumentos da taxa de inflação obrigam o Banco Central a aumentar a taxa básica de juros na tentativa de impedir uma divergência dos índices de inflação com respeito à meta inflacionária. Isso aumenta a volatilidade da taxa básica de juros, contribuindo para o aumento do risco de juros (cf. Ono et alli, 2004), obrigando os bancos comerciais a aumentar o spread entre a sua taxa e a taxa de juros fixada pelo Banco Central. Por fim, iremos supor que o mark-up bancário possui um piso abaixo do qual ele não pode cair, o qual reflete o grau de monopólio dos bancos. Dessa forma, a equação de determinação do mark-up bancário é dada por:

$$
z_{t}^{b}=\max \left(z_{\min }^{b} ; z_{0}+z_{1}^{b} u_{t-1}+z_{2}^{b} \pi_{t-1}\right) ; z_{1}^{b}<0 ; z_{2}^{b}>0
$$

Uma vez fixada a taxa de juros dos empréstimos, os bancos comerciais atendem a toda a demanda de empréstimos das firmas do setor produtivo. Isso significa que não há nenhum tipo de restrição de crédito, tal como se observa nos modelos macroeconômicos de inspiração novo-keynesiana. Portanto, o volume efetivo de crédito concedido pelos bancos comerciais no período $t$ é inteiramente determinado pela demanda de crédito, em consonância com a hipótese de endogenidade da oferta de moeda, apresentada por Kaldor (1982) e Moore (1988). ${ }^{26}$

\footnotetext{
${ }^{26} \mathrm{O}$ argumento básico de Moore para justificar a endogenidade da oferta de moeda é que, nas condições prevalecentes nos modernos sistemas monetários, caracterizado pela existência conjunta de fiat money e credit money, a base monetária é endógena, ou seja, o Banco Central acomoda toda e qualquer variação na demanda por reservas bancárias com uma variação da disponibilidade de reservas, mantendo constante a taxa de juros do mercado interbancário.
} 


\section{METODOLOGIA DE SIMULAÇÃO ${ }^{27}$}

O modelo apresentado na seção anterior não admite solução analítica fechada. Dessa forma, deve-se proceder à realização de simulações em computador para a obtenção de trajetórias em aberto, ou seja, fora do equilíbrio, para as variáveis endógenas.

Nesse contexto, se coloca uma questão fundamental, a saber: como atribuir valores numéricos para os parâmetros e as condições iniciais do sistema? No presente artigo optamos pela utilização do método de calibração, o qual é definido, com base em Hansen e Heckman (1996, p. 92), como um processo de manipulação das variáveis independentes - leia-se aqui os parâmetros e as condições iniciais - de modo a obter uma combinação plausivel entre os dados observados empiricamente e os resultados simulados. ${ }^{28}$

Esse método encontra respaldo no assim chamado princípio da correspondência, enunciado por Paul Samuelson em seu livro clássico Foundations of Economic Analysis (1947). Segundo Samuelson, durante a calibração de um modelo, o pesquisador pode se deparar com a ausência de dados quantitativos precisos sobre os valores dos parâmetros (e das condições iniciais) de um sistema dinâmico. No entanto, ele precisa inferir analiticamente o movimento de um sistema complexo. Nessa situação, o pesquisador deve fixar os valores dos parâmetros a fim de estabelecer uma correspondência realista entre as variáveis estáticas (parâmetros) e as variáveis dinâmicas (variáveis dependentes).

Essas considerações nos permitem estabelecer a seguinte metodologia de calibragem do modelo macrodinâmico apresentado na seção anterior:

1. Atribui-se um conjunto inicial de valores para os parâmetros e condições iniciais, procurando, na medida do possível, utilizar estimativas empiricamente plausíveis para os mesmos.

2. Rodar o modelo em computador de forma a obter as trajetórias dinâmicas das variáveis endógenas.

3. Verificar se as trajetórias dinâmicas assim obtidas replicam algumas propriedades gerais ou "fatos estilizados" observados nas economias capitalistas.

4. Caso as trajetórias dinâmicas geradas pelo conjunto inicial de parâme-

\footnotetext{
${ }^{27}$ Sobre os desenvolvimentos recentes da metodologia de simulação ver Werker \& Brenner (2004).

${ }^{28}$ Essa metodologia de simulação obviamente não é a mesma adotada por Kydland e Prescott (1996). Em resposta ao comentário feito por um parecerista anônimo a respeito do "equívoco" do método de calibragem aqui empregado, devemos dizer que a calibragem de modelos teóricos com vistas à simulação computacional não é monopólio da teoria dos ciclos reais de negócios, tendo sido um método extensamente utilizado por autores pós-keynesianos muito anteriormente ao advento da teoria em consideração. Com efeito, autores pós-keynesianos como Kalecki (1954), Kaldor e Mirless (1961), Goodwin (1967) e mais recentemente Possas et alli (2004) utilizaram extensamente o método aqui descrito como forma de obtenção de resultados a partir de seus modelos analíticos.
} 
tros não sejam empiricamente plausiveis, ou seja, se as mesmas não estiverem em conformidade com os "fatos estilizados" da dinâmica capitalista, deve-se escolher um novo conjunto de valores e repetir o experimento.

A metodologia acima definida nos coloca duas questões fundamentais. A primeira refere-se ao momento no qual o pesquisador deve encerrar a sua busca por um conjunto plausível de parâmetros. A segunda questão está relacionada com a seleção dos "fatos estilizados" da dinâmica capitalista, os quais são utilizados como padrão de comparação para as trajetórias dinâmicas geradas pelo modelo teórico.

No que se refere à primeira questão, deve-se observar que não há nenhum critério objetivo com base no qual se possa determinar qual é o momento em que o pesquisador deve encerrar a sua busca por um conjunto plausível de parâmetros. Nesse contexto, o pesquisador não tem outra opção a não ser utilizar a racionalidade limitada de Simon (1980) e se contentar com um bom conjunto de parâmetros, ainda que possam existir parâmetros melhores, ou seja, um conjunto de parâmetros que fosse capaz de gerar trajetórias dinâmicas mais aderentes àquelas que se observam no mundo real.

Uma crítica comum ao procedimento exposto acima é que a grande complexidade dos modelos de simulação em conjunto com a existência de parâmetros livres, ou seja, parâmetros cujos valores numéricos precisos não tem embasamento empírico, proporcionam, ao construtor do modelo, graus de liberdade quase infinitos na obtenção dos resultados desejados. Em outras palavras, o pesquisador poderia obter virtualmente qualquer resultado a partir de seu modelo teórico desde que disponha do tempo e da paciência necessários para testar diversos conjuntos de valores dos parâmetros até obter um conjunto de valores que lhe proporcione o resultado desejado.

Essa crítica é apenas parcialmente correta. Com efeito, a obtenção de um bom conjunto de parâmetros envolve um processo de tentativa e erro no qual os resultados obtidos a partir de uma determinada especificação numérica do modelo são contrastados com uma série de fatos estilizados. Contudo, os graus de liberdade do pesquisador podem ser substancialmente reduzidos se o número de fatos estilizados a serem explicados for suficientemente grande. Então contexto, um modelo ruim, isto é, um modelo que abstrai algum aspecto essencial da realidade econômica, não será capaz de explicar uma boa quantidade desses fatos estilizados, qualquer que seja o conjunto de valores escolhidos para os parâmetros e para as condições iniciais. Dessa forma, a seleção de um número razoavelmente grande de fatos estilizados sobre a dinâmica das economias capitalistas tornase um elemento essencial não só para a realização de um bom processo de calibragem dos parâmetros do modelo, como também um critério de julgamento da relevância e da plausibilidade do modelo que está sendo apresentado.

No que se refere aos fatos estilizados, existe um relativo consenso entre os economistas a respeito dos traços gerais da dinâmica capitalista. Esses traços gerais são os seguintes: 
a. O PIB real apresenta uma inequívoca tendência de crescimento no longoprazo, mas esse crescimento se dá por intermédio de flutuações irregulares, mas não-explosivas, do PIB real (cf. Blanchard e Fisher, 1989, p. 1).

b. A distribuição funcional da renda entre salários e lucros é relativamente estável no longo-prazo (cf. Kaldor, 1957).

c. A taxa de retorno sobre o capital não apresenta nenhuma tendência clara à queda ao longo do tempo (cf. Kaldor, 1957).

d. As quedas abruptas do nível de atividade econômica, ou seja, aquilo que se convencionou chamar de depressão, são um fenômeno relativamente raro na dinâmica capitalista. Em outras palavras, depressões só ocorrem uma ou duas vezes ao longo de um século (cf. Leijonhufvud, 1996). ${ }^{29}$

Ao todo são 29 parâmetros e quinze valores iniciais para o sistema. ${ }^{30}$ Desses 29 parâmetros, existem estimativas confiáveis para nove parâmetros, a saber: $\pi^{*}, \eta$, $s_{\mathcal{G}}, s_{f}, s, t, g^{\max }, u^{\max } e U^{\min }$. Essas estimativas são fornecidas pela experiência histórica das economias capitalistas avançadas. Por exemplo, nenhuma economia capitalista desenvolvida experimentou uma taxa de desemprego menor do que $2 \%$ nos últimos 80 anos. Por outro lado, os bancos centrais de todos os países desenvolvidos que adotaram o regime de metas de inflação durante a década de 1990 têm como meta inflacionária uma inflação inferior a $5 \%$ ao ano (cf. Bernanke et alli, 1999). Por fim, uma propensão a poupar a partir dos rendimentos não-salario de $20 \%$ não parece ser um número irrealista para as economias capitalistas desenvolvidas, assim como uma alíquota média de impostos na ordem de $20 \%$. $^{31}$

No que se refere aos demais parâmetros, embora não tenhamos uma estimativa precisa a respeito da ordem de grandeza dos mesmos, podemos utilizar os resultados dos estudos empíricos existentes para avaliar o sinal de pelo menos alguns deles. Por exemplo, o estudo de Aronovich (1994) mostrou que, no caso da economia brasileira no período 1986-1992, o mark-up bancário varia positivamente com a taxa de inflação e negativamente com o grau de utilização da capacidade produtiva, justificando assim os sinais assumidos para os coeficientes $\cdot z_{1}^{b}$ $e z_{2}^{b}$ na Tabela I.

\footnotetext{
${ }^{29}$ Com efeito, ao longo do século XX, as economias capitalistas desenvolvidas só experimentaram um único episodio de queda catastrófica do nível de atividade econômica, a saber: a grande depressão de 1929.

${ }^{30}$ As condições iniciais dão apenas a escala do sistema de forma que a escolha do valor numérico para as mesmas não é uma questão particularmente relevante.

${ }^{31}$ Com efeito, segundo dados do Banco Mundial (2001), a poupança doméstica como proporção do PIB nos Estados Unidos foi de 18.1\% no período 1970-1999, ao passo que a arrecadação média de impostos como proporção do PIB foi de 17,5\%.
} 
Tabela I: Parâmetros e condições iniciais usadas na simulação do modelo

\begin{tabular}{|c|c|c|c|c|c|}
\hline Parâmetro & Valor & Parâmetro & Valor & Variável em $t=$ & 0 Valor \\
\hline$\sigma$ & 0.8 & $\pi^{*}$ & 0.05 & $\mathrm{C}_{0}$ & 500 \\
\hline$h^{\prime}$ & 0.035 & $\eta$ & 0.018 & $\mathrm{I}_{0}$ & 30 \\
\hline hc & 0.15 & $\mathrm{~s}_{\mathrm{c}}$ & 0.2 & $\mathrm{G}_{0}^{\mathrm{C}}$ & 70 \\
\hline$\alpha_{0}$ & 0.05 & $s_{f}$ & 0.2 & $\mathrm{G}_{0}^{\mathrm{i}}$ & 10 \\
\hline$\alpha_{1}$ & 0.05 & $\tau$ & 0.2 & $z^{f}$ & 0.39 \\
\hline$z_{0}$ & 0.04 & $z_{1}^{b}$ & -0.05 & $\mathrm{~K}_{0}$ & 1500 \\
\hline$z_{1}^{\dagger}$ & 0.65 & $z_{2}^{b}$ & 0.5 & $\mathrm{P}_{0}$ & 2.8 \\
\hline$z_{2}^{\dagger}$ & 0.1 & $\psi$ & 0.03 & $\mathrm{w}_{0}$ & 2.0 \\
\hline$\theta$ & 0.85 & $\varphi$ & 0.3 & $\mathrm{~N}_{0}$ & 600 \\
\hline$\gamma$ & 0.0 & $\phi_{0}$ & 0.3 & Nmax & 900 \\
\hline$\lambda$ & 0.05 & $\phi_{1}$ & 0.73 & $i_{0}^{*}$ & 0.1 \\
\hline$\beta_{0}$ & 7 & $\mathrm{~g}^{\max }$ & 0.1 & $\mathrm{~L}_{0}$ & 200 \\
\hline$\beta_{1}$ & 30 & Umin & 0.02 & $\mathrm{DG}_{0}$ & 0.0 \\
\hline \multirow[t]{2}{*}{$\beta_{2}$} & -0.25 & $v^{\max }$ & 0.9 & $\mathrm{H}_{0}$ & 200 \\
\hline & & $\delta^{\max }$ & 0.75 & $\mathrm{D}_{0}$ & 200 \\
\hline
\end{tabular}

\section{PRIMEIROS RESULTADOS DA SIMULAÇÃO}

O modelo exposto na seção 2 foi rodado em planilha EXCEL com os valores assumidos na Tabela I acima para um horizonte de tempo de 75 períodos. ${ }^{32}$ O primeiro resultado interessante obtido com o modelo foi a ocorrência de um crescimento irregular, mas não explosivo, do PIB real, como podemos visualizar nas Figuras 1 e 2 abaixo:

${ }^{32}$ Como os valores dos parâmetros apresentados na Tabela I são valores anuais (exemplo, a meta inflacionária de $5 \%$, ou a recíproca da relação capital-produto de 0.8 ); segue-se que o período de simulação corresponde a 75 anos. 
Figura 1: Evolução do PIB no Brasil

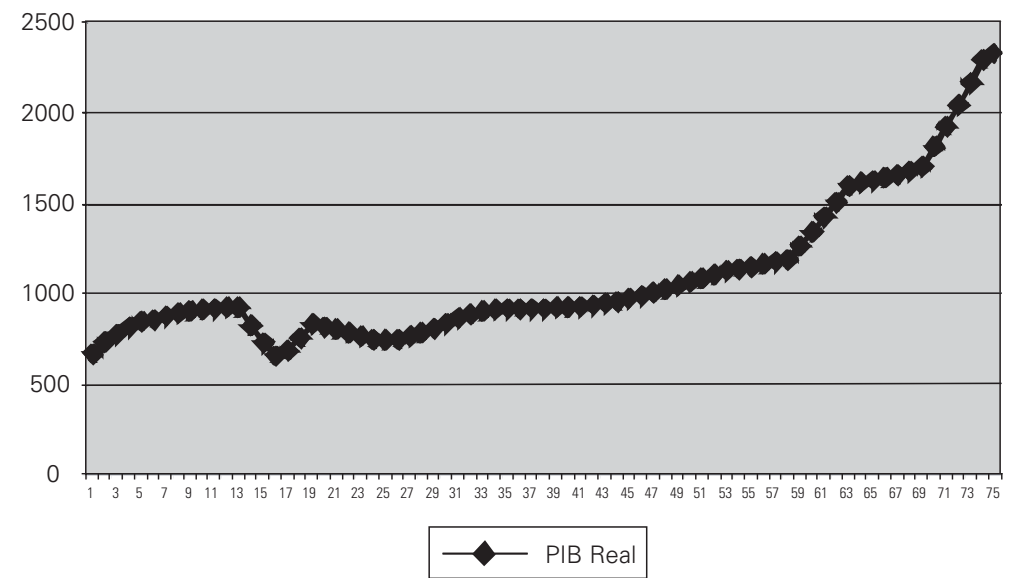

Observa-se claramente na Figura 2 que (i) a taxa de crescimento do produto real flutua ao longo do tempo, ou seja, a economia apresenta "crescimento cíclico"; (ii) o padrão de flutuação é altamente irregular, apresentando uma amplitude mais alta nos períodos iniciais, a qual é substancialmente reduzida após o período 28 e volta a aumentar após o período 56; (iii) a economia apresenta um único episódio de depressão ao longo dos 75 períodos de simulação: por volta do período 13, a economia experimenta uma redução do nível de atividade econômica superior a $10 \%$ por período ao longo de um intervalo de tempo não superior a cinco períodos; (iv) as flutuações observadas da taxa de crescimento do produto real não apresentam nenhuma tendência discernível a aumentarem ao longo do tempo, ou seja, as flutuações do produto real não são explosivas.

Figura 2: Dinâmica da taxa de crescimento do produto real

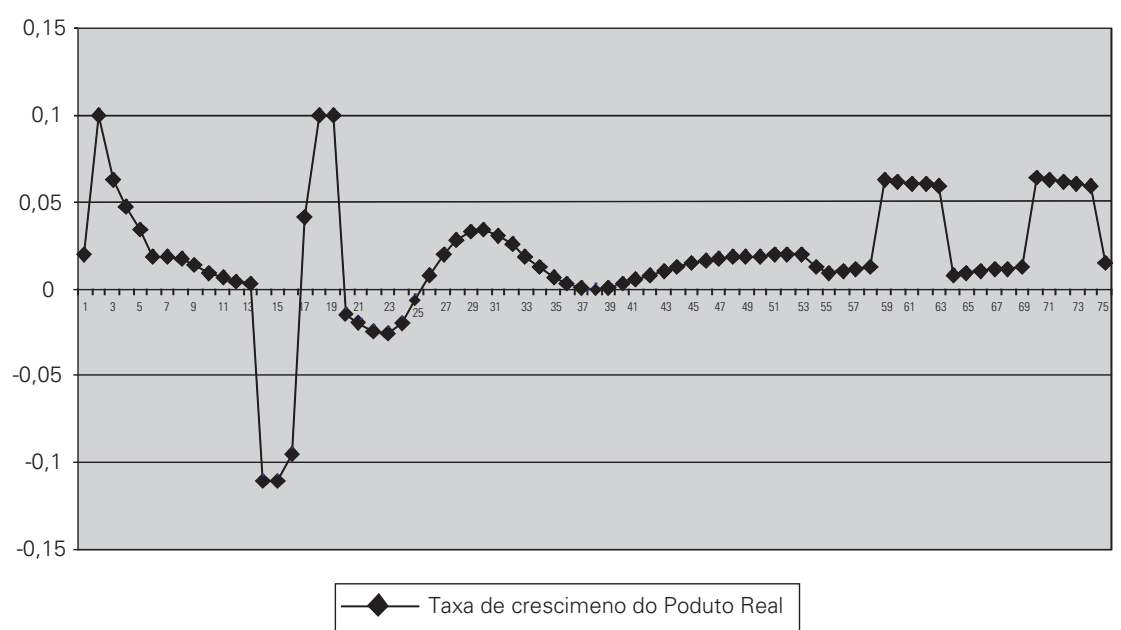


A "grande depressão" observada nos estágios iniciais da simulação é precedida por um processo de crescente fragilização financeira das empresas do setor produtivo, tal como pode ser observado na Figura 3 abaixo.

Figura 3: Dinâmica da fragilidade financeira

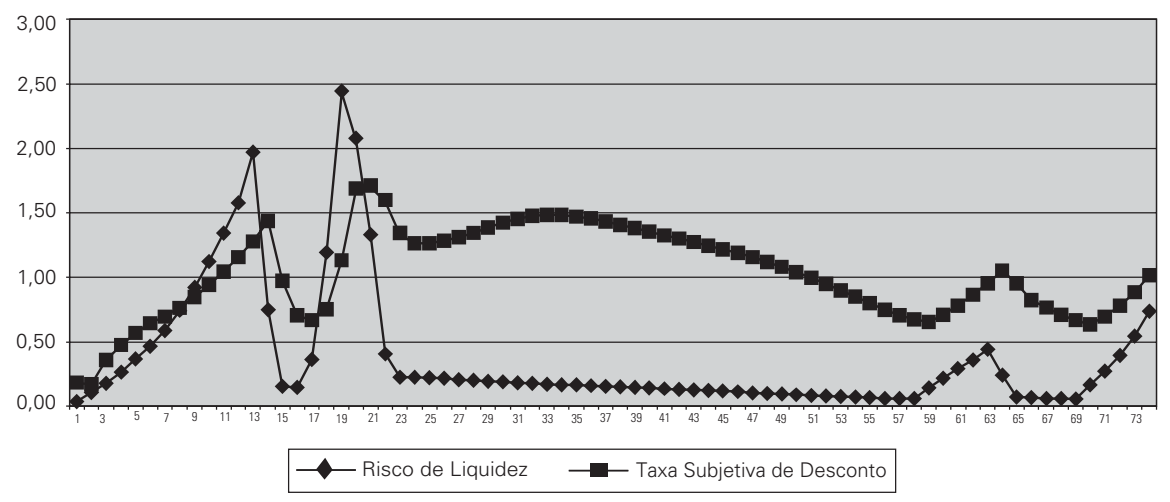

A crise do período 13 é resultado do violento processo de desinflação engendrado pelo Banco Central. Com efeito, tal como podemos observar na Figura 4, nos estágios iniciais da simulação, a taxa efetiva de inflação diverge progressivamente da meta inflacionária de $5 \%$ por período, alcançando um patamar de $17 \%$ por período no período 13. Em função do regime de metas de inflação prevalecente nessa economia, o Banco Central inicia um processo de elevação da taxa básica de juros já no período 2 . Entre os períodos 3 e 15, a taxa básica de juros permanece num patamar superior a $20 \%$ por período, produzindo uma fragilização crescente das posições financeiras das empresas do setor produtivo, a qual resulta na "grande depressão".

A Figura 4 mostra ainda uma propriedade interessante da dinâmica capitalista, qual seja: a existência de sub-utilização da capacidade produtiva no longoprazo. Com efeito, após a recuperação da "crise do período 13", o grau de utilização da capacidade produtiva aumenta de forma bastante acentuada ate o período 55 , após o qual se estabiliza em torno de $88 \%{ }^{33}$.

\footnotetext{
${ }^{33}$ No final do período de simulação, o grau de utilização da capacidade produtiva se aproxima do teto definido na Tabela I, se igualando ao mesmo durante alguns períodos, mas permanecendo via-deregra abaixo do mesmo.
} 


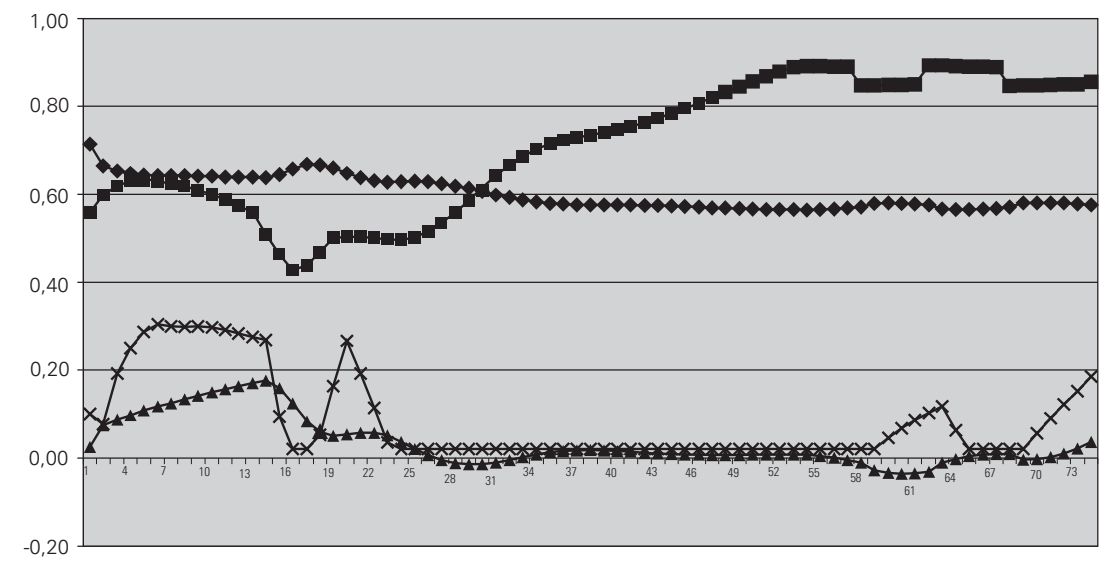

Salário Real — Utilização da Capacidade $\longrightarrow$ - Inflação $\rightarrow$ Taxa Básica de Juros

As simulações do modelo teórico foram ainda capazes de replicar dois fatos estilizados da dinâmica capitalista, a saber: a estabilidade da distribuição funcional da renda e a estabilidade da taxa de lucro no longo-prazo. Essa afirmação pode ser facilmente constatada pelas Figuras 6 e 7 abaixo. Observemos na Figura 6 que a participação dos lucros na renda se estabiliza em torno de $50 \%$ do PIB, um valor próximo ao encontrado, por exemplo, na economia italiana.

A Figura 7 nos revela ainda duas outras propriedades interessantes da dinâmica da economia em consideração. Em primeiro lugar, constata-se que na maior parte do tempo, a taxa de retorno do capital é superior à taxa real de juros, a qual é definida como a diferença entre a taxa de juros dos empréstimos bancários e a taxa de inflação. Em segundo lugar, constatamos que a taxa de lucro se estabiliza em torno de $32 \%$ por período, que é um valor alto, mas empiricamente plausível.

Figura 6: Dinâmica da participação nos lucros

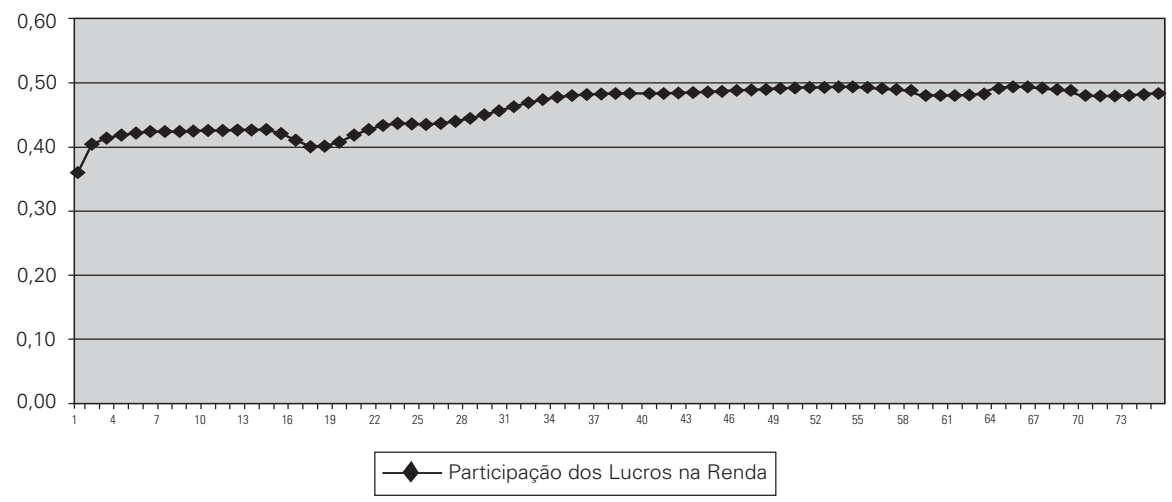




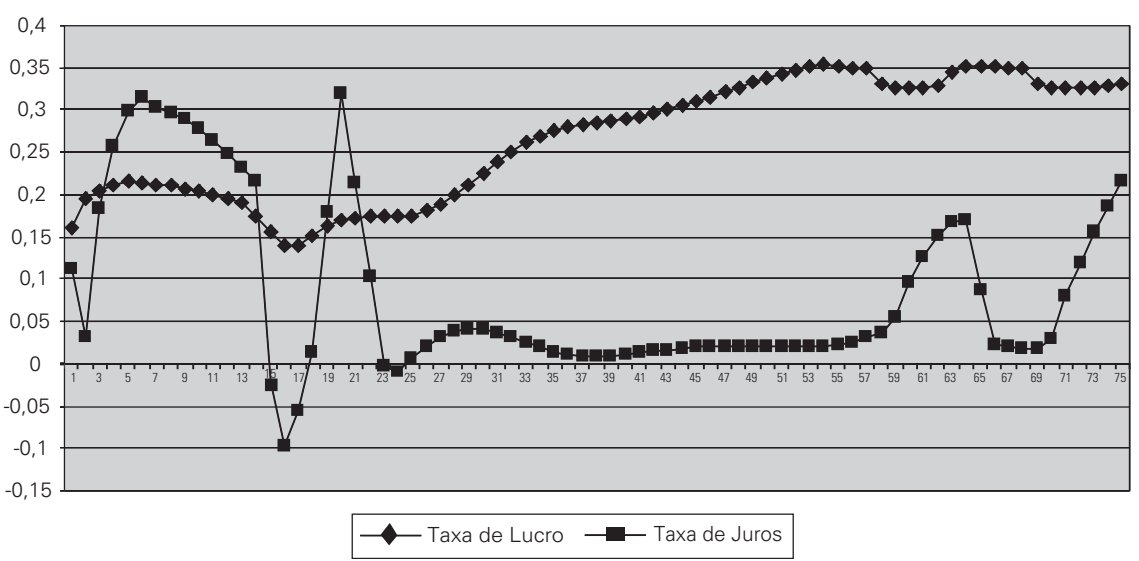

Uma primeira implicação de política econômica que pode ser tirada dos resultados da simulação do modelo aqui apresentado refere-se à condução da política de redução da taxa de inflação. A crise do período 13 foi o resultado da tentativa do Banco Central de reduzir a taxa de inflação de $17 \%$ por período para $5 \%$ por período. Apesar do alto coeficiente de suavização dos movimentos da taxa de juros assumido pela simulação, a manutenção da taxa básica de juros em patamares elevados por um longo período produziu uma fragilização crescente das posturas financeiras das empresas do setor produtivo, a qual culminou com uma acentuada queda do nível de atividade econômica. Daqui se segue que um princípio básico que o Banco Central deve utilizar na condução da política monetária é o de jamais engendrar quedas muito acentuadas da taxa de inflação. Isso porque, devido à presença de inércia inflacionária e aos efeitos da taxa de juros sobre a posição financeira das firmas, uma redução muito acentuada da taxa de inflação irá resultar num grande aumento da fragilidade financeira das empresas e, mais cedo ou mais tarde, numa queda acentuada do nível de atividade econômica.

\section{CONCLUSÃO}

Ao longo do presente artigo apresentamos a estrutura e os primeiros resultados de simulação de um modelo macrodinâmico que incorpora vários dos princípios teóricos pós-keynesianos. Os primeiros resultados da simulação computacional do modelo reproduzem alguns traços gerais da dinâmica capitalista como, por exemplo, a natureza irregular, mas não explosiva, das flutuações do produto real ao longo do tempo; a estabilidade da taxa de lucro e da distribuição funcional da renda no longo-prazo; persistência da sub-utilização da capacidade produtiva e o caráter raro da ocorrência de quedas catastróficas do produto real. Uma implicação importante de política econômica que pode ser tirada do pre- 
sente modelo é a idéia de que o Banco Central deve conduzir a política monetária de forma a jamais engendrar quedas muito abruptas da taxa de inflação.

\section{REFERÊNCIAS BIBLIOGRÁFICAS}

ARONOVICH, S. (1994). "Uma nota sobre os efeitos da inflação e do nível de atividade sobre o spread bancário". Revista Brasileira de Economia, vol. 48, n. 1, jan-mar.

BANCO MUNDIAL. (2001). World Development Indicators. Washington: The World Bank. CDROM.

BARBOSA, F.H. (2004). "A inércia da taxa de juros na política monetária”. Ensaios Econômicos N 534. Rio de Janeiro. Fundação Getúlio Vargas.

BERNANKE, B. et alli (1999). Inflation Targeting: lessons from the international experience. Princeton. Princeton University Press.

BLANCHARD, O. (1999). Macroeconomia: Teoria e política econômica. Rio de Janeiro. Campus $1^{2}$ edição.

BLANCHARD, O.; FISHER, S. (1989). Lectures on Macroeconomics. Cambridge (mass.) MIT Press.

BLINDER, A. (1999). Bancos Centrais: teoria e prática. São Paulo. Editora 34.

BRESSER-PEREIRA, L.C; NAKANO, Y. (1984). Inflação e Recessão: A teoria da inércia inflacionária. São Paulo. Brasiliense.

CARVALHO, F.C. (1992). Mr. Keynes and the Post Keynesians: principles of macroeconomics for a monetary production economy. Aldershot. Edward Elgar.

DAVIDSON, P. (1988). "A Technical Definition of Uncertainty and the Long-Run Neutrality of Money”. Cambridge Journal of Economics, vol. 12.

DAVIDSON, P. (1994). Post Keynesian Macroeconomic Theory. Aldershot. Edward Elgar.

DOMAR, E. (1946). "Capital Expansion, Rate of Growth and Employment". Econometrica, vol. 14.

EICHNER, A. (1980). The Megacorp and the Oligopoly. Armmonk. M.E. Sharpe.

HICKS, J. (1950). A Contribution to the Theory of the Trade Cycle. Oxford. Oxford University Press. GOODWIN, R. (1967). "A Growth Cycle” in Essays in Economic Dynamics. MacMillan: Londres.

HANSEN, L; HECKMAN, J. (1996). “The Empirical Foundations of Calibration”. Journal of Economic Perspectives, vol. 10, n. 1.

KALDOR, N. (1956). “Alternative Theories of Distribution”. Review of Economic Studies, vol. 23, $\mathrm{n} 2$.

KALDOR, N.. (1957). “A Model of Economic Growth”. Economic Journal, vol. 67.

KALDOR, N.. (1982). The Scourge of Monetarism. Oxford. Oxford University Press.

KALDOR, N; MIRRLEES, J.A. (1962). “A New Model of Economic Growth”. Review of Economic Studies, vol. 29, pp. 174-92.

KALECKI, M. (1954). Theory of Economic Dynamic. LondresAllen \& Unwin, 2 Edição.

KEYNES, J.M. (1936). The General Theory of Employment, Interest and Money. Londres. Macmillan.

KYDLAND, F; PRESCOTT, E. (1996). "The computational experiment: an econometric tool". Journal of Economic Perspectives, vol. 10, n.1, pp. 69-85.

LEIJONHUFVUD, A. (1996). "Towards a Not Too Rational Macroeconomics" in Collander, D. (Ed.) Beyond Microfoundations: post walrasian macroeconomics. Cambridge: Cambridge University Press.

LUCAS, R.; SARGENT, T. (1994). “After Keynesian Macroeconomics”, in Miller, P (org.). The Rational Expectations Revolution in Economics. Cambridge MIT Press. (Edição original: 1979).

MARX, K. (1988). O Capital: crítica da economia política. São Paulo. Nova Cultural.

MINSKY, H.P. (1975). John Maynard Keynes. Columbia University Press: Nova Iorque.

MOORE, B. (1988). Horizontalists and Verticalists: The Macroeconomics of credit money. Cambridge. Cambridge University Press. 
ONO, F H; SILVA, G. J; OREIRO, J. L; PAULA, L. F. (2004). "Determinantes macroeconômicos do spread bancário no Brasil: Teoria e evidência recente”. Mimeo. Disponível em: www.ie.ufrj.br/moeda.

PASINETTI, L. (1962). "Rate of Profit and Income Distribution in Relation to the Rate of Economic Growth". Review of Economic Studies, vol. 29, nœ4.

PASINETTI, L. (1997). “The Principle of Effective Demand” in Harcourt, G.C; Riach, P (orgs.). A Second Edition of the General Theory. Londres. Routledge.

POSSAS, M.L. (1984). "Um modelo dinâmico multissetorial”. Pesquisa e Planejamento Econômico, 14(2).

POSSAS, M.L. (1993). "Racionalidade e Regulariedades: rumo a uma integração micro-macrodinâmica”. Economia e sociedade, vol. 2.

POSSAS, M.L; DWECK, E; VISCONTI, A.C. (2004). "Um modelo macrodinâmico multissetorial”. Texto para Discussão 003/2004. IE/UFRJ.

ROBINSON, J. (1988). “Un Modelo de Acumulación” In: Ocampo, J.A (org.). Economía PosKeynesiana. Cidade do México. Fondo de Cultura. (Edição original: 1962).

ROUSSEAS, S. (1986). Post Keynesian Monetary Economics. Ann Arbor. MacMillan.

SAMUELSON, P. (1939). "Interaction Between the Multiplier and the Principle of Acceleration". Review of Economic Studies, vol. 21, Maio.

SIMON, H. (1980). “A Racionalidade do Processo Decisório em Empresas”. Edições Multiplic, vol.1, n 1.

TAYLOR, J.B. (1993). "Discretion versus Policy Rules in Practice” in Cornegie-Rochester Conference Series on Public Policy, vol. 39, pp. 195-214. Disponível em: www.stanford.edu/johntayl/Papers/Discretion.Pd

TAYLOR, J.B. (1947). Foundations of Economic Analysis. Cambridge. Harvard University Press (mass.).

SECURATO, J.R. (2002). Crédito - Analise e avaliação do risco. São Paulo. Editora Saint Paul.

STEINDL, J. (1952). Maturity and Stagnation in American Capitalism. Oxford. Basil Blackwell.

WERKER, C; BRENNER, T. (2004). "Empirical Calibration of Simulation Models". Papers on Economics \& Evolution \#0410, Max Planck Institute for Research Into Economic Systems, Jena (Alemanha). 